\title{
Urban Growth Monitoring using Remote Sensing and Geo-Informatics: Case Study of Gandhinagar, Gujarat State (India)
}

\author{
Bhavika Badlani' ${ }^{1}$, Ajay N. Patel ${ }^{2}$, Krunal Patel2, Manik H. Kalubarme ${ }^{2 *}$ \\ ${ }^{1}$ Institute of Technology, Nirma University, Ahmedabad, India \\ ${ }^{2}$ Department of Science \& Technology, Bhaskaracharya Institute for Space Applications and Geo-Informatics (BISAG), \\ Government of Gujarat, Gandhinagar, India \\ Email: *mhkalubarme@gmail.com
}

How to cite this paper: Badlani, B., Patel, A.N., Patel, K. and Kalubarme, M.H. (2017) Urban Growth Monitoring using Remote Sensing and Geo-Informatics: Case Study of Gandhinagar, Gujarat State (India). International Journal of Geosciences, 8, 563-576. https://doi.org/10.4236/ijg.2017.84030

Received: March 6, 2017

Accepted: April 25, 2017

Published: April 28, 2017

Copyright (C) 2017 by authors and Scientific Research Publishing Inc. This work is licensed under the Creative Commons Attribution International License (CC BY 4.0).

http://creativecommons.org/licenses/by/4.0/

\begin{abstract}
The Gandhinagar town has undergone unprecedented urban growth after assuming the status of a capital of Gujarat state, India in 1971. The Gandhinagar city lies on the western bank of river Sabarmati and city is also known as the "Tree capital of India" because of greenery with $54 \%$ green cover. The urban sprawl in Gandhinagar town was analyzed using multi-temporal Landsat TM data from 1981 to 2015. Spectral indices namely Normalized Difference Vegetation Index (NDVI), Normalized Difference Built-up Index (NDBI) and Built-up Index (BUI) were generated from the Landsat TM bands covering visible Red (R), Near Infrared (NIR) and Short Wave Infrared (SWIR) wavelength regions. Spectral variations in built-up, open spaces, urban vegetation and water areas were studied by generating two-dimensional spectral plots of NDBI and BUI. The spectral response of built up areas like Urban-dense and urban-sparse classes are quite distinct from other cover types like open spaces, urban vegetation and water. The results indicate that the normalized difference built-up index (NDBI) and Built-up Index (BUI) were very useful for mapping urban built-up areas in Gandhinagar town using Landsat Thematic Mapper (TM) data. The built-up area in Gandhinagar increased from 1100.1 ha during Jan 1989 to 1907.3 ha during Jan 2015 which indicates about 73 per cent increase in the built-up area during the period of 26 years. The urban vegetation which includes parks and gardens in the city has also shown increasing trend during the period of 1989 to 2015 . However, the area under open spaces has decreased as the development of built-up area has increased as per development plan of the Gandhinagar town.
\end{abstract}

\section{Keywords}

Landsat-TM, Normalized Difference Vegetation Index (NDVI), Normalized 
Difference Built-up Index (NDBI), Built-up Index (BUI), Urban Sprawl monitoring

\section{Introduction}

The ever increasing population has led to the rise in unplanned urban growth in the suburbs of the city which is usually termed as urban sprawl [1] [2]. Urban growth on one hand is an indicator of economic, social and political growth whereas, on the other hand it is at the cost of forests, agriculture lands, orchards and greenery of the city [3] [4]. Bhatta et al., 2010 [5] had described the urban sprawl as an unplanned and uneven pattern of growth driven by various processes finally leading to inefficient resource utilization. Urban growth management is critical in the continued growth of a city. The trend specified, using conventional land surveys by department authorities, focuses on land usage, and is often inaccurate in its depictions of how studied lands are actually used. The pace of urbanization is adversely affecting the green cover in the urban areas. With expanding urbanization in the twentieth century, the tree cover in urban areas around the world is declining due to the demand of the area for development. The identification (location, distribution and size) of the built-up area is of major importance in urban, suburban and agricultural studies. The calculation of its change throughout the time to the detriment of the non-built-up area constitutes a highly important indicator of urban change and environmental degradation [6] [7] [8] [9] [10]. Remote sensing provides reliable scientific tools for the calculation of the built-up area, using intertemporal satellite images and studying the multispectral space.

\subsection{Remote Sensing and GIS Applications for Urban Growth Monitoring}

Remote sensing offers several advantages over conventional ground methods used to map and monitor urban growth. Several studies have analysed urban sprawl at regional, local and temporal scales [11] [12]. Another practical advantage of utilizing RS data for urban studies is the availability of historical archives that can help in mapping and understanding urban sprawl over time [8]. The urbanization pattern of the greater Asmara area in Eritrea was studied using satellite remote sensing data of Landsat. They analysed land use/ land cover change using a data object based image analysis and urban sprawl using Shannon entropy [13]. Urban sprawl of the Ajmer city (Rajasthan) was studied at mid-scale level for 25 years (1977-2002) where they used Landsat TM, MSS, ETM+, and IRS LISS III data [14]. Landsat imagery of Kansas City of United States of America (USA) was used to generate a time series of land cover data over the past three decades [15]. Long term trends and patterns of urban sprawl were studied in south India and its surrounding area, by [16] using IRS P6 data and topographic sheets in the GIS domain along with Shannon's entropy model 
to assess the urban sprawl. In the Udupi district of Karnataka state in India, Urban sprawl patterns were analysed using (LISS and PAN images of 2003 and LISS IV and Cartosat images of 2013), which showed that barren/waste land was also converted to settlement/built up area [17]. The urban sprawl in Ranchi city was analysed, using Landsat data from 1976, 2002 and 2015. The study revealed that the annual urban growth rate was $1.76 \mathrm{ha} / \mathrm{yr}$ over the period from 1976 to 2002 whereas the annual growth rate was 2 ha/yr over the period from 2002 to 2015. The northern side of the city has witnessed more expansion in 2002 when compared with the growth in 1976 [18].

\subsection{Remote Sensing Based Indices for Urban Growth Monitoring}

Remote sensing images are useful for monitoring the spatial distribution and growth of urban built-up areas because of their ability to provide timely and synoptic views of land cover [8] [12] [19]. Zha et al., 2003 [20] proposed the normalized difference built-up index (NDBI) to automatically map urban built-up areas. The method takes advantage of the unique spectral responses of built-up areas and other land covers. Built-up areas are effectively mapped through the arithmetic manipulation of recoded NDVI and NDBI images derived from Landsat Thematic Mapper (TM) imagery. However, the approach proposed by Zha et al., 2003 [20] recodes the derived NDBI and NDVI images to create binary images under the assumption that a positive value of NDBI should indicate built-up areas and a positive value of NDVI should indicate vegetation. As discussed by Zha et al., 2003 [20], with this recoding process, their approach is unable to separate urban areas from barren and bare land. Therefore, He, et al, 2010 [21], proposed new method which eliminates the original assumption that a positive NDBI value should indicate built-up areas and a positive normalized difference vegetation index (NDVI) value should indicate vegetation. The new method uses a semiautomatic segmentation approach which has improved universality and lower commission error compared with the original method. Dimitris and Patias, 2016 [22] developed new index BUI (Built-Up Index) which combines the bands of Landsat ETM+: RED (band 3), SWIR1 (band 5) and SWIR2 (band 7).

\section{Objectives}

This study was carried out in Gandhinagar town with major objective to map changes in built up area in Gandhinagar town using multi-temporal satellite data from 1981 to 2015. The detailed objectives of this study are as follow:

- Generate three indices namely NDVI, NDBI and BUI using Landsat TM bands covering visible Red (R), Near Infrared (NIR) and Short Wave Infrared (SWIR) wavelength regions.

- Study the spectral responses of built-up, vegetation and water areas in the NDVI, NDBI and BUI images.

- Monitoring Urban Growth of Gandhinagar Town using Multi-temporal Satellite data of last 35 years (1981 to 2015). 


\section{Material and Methodology}

\subsection{Study Area}

Gandhinagar got an identity of its own when the state of Mumbai was divided into two separate states of Gujarat and Maharashtra. In the beginning, Ahmedabad-a commercial hub of Gujarat was chosen as the state capital and it was proposed that a new capital should be constructed along the line of other new state capitals, particularly Chandigarh. Named after Mahatma Gandhi the foundation stone of this city was laid on 1965 and in 1971 the capital was shifted from Ahmedabad to Gandhinagar. The Gandhinagar district includes four talukas-Mansa, Kalol, Dahegam and Gandhinagar. It is bounded by Mahesana, Patan, Sabarkantha and Banaskantha. All kinds of head offices of state government, secretariat of all departments, offices and residents of ministers of legislative assembly, residence of governor and other important offices are situated in Gandhinagar. The average elevation of Gandhinagar town is $81 \mathrm{~m}$ (266 feet) above MSL. The city lies on the western bank of river Sabarmati. Gandhinagar city is also known as the "Tree capital of India" because of greenery with $54 \%$ green cover. Gandhinagar town lies between $23.0^{\circ} \mathrm{N}$ to $23.6^{\circ} \mathrm{N}$ Latitude and $72.3^{\circ} \mathrm{E}$ to $73.7^{\circ} \mathrm{E}$ Longitude. The $388 \mathrm{sq} \mathrm{km}$ area under Gandhinagar Urban Development Authority (GUDA) includes the $57 \mathrm{sq} \mathrm{km}$ area under the Gandhinagar Municipal Corporation (GMC). Gandhinagar-the capital of Gujarat undergoes constant development. The built-up area, vegetative cover, barren land, the area covered with water bodies-everything changes in the process. The location map of the study area is given in Figure 1. The development plan of the Gandhinagar town from 1967 to 2004 indicating development of various sectors during each decade is given in Figure 2.

\subsection{Data Used}

In this study, satellite data from Landsat TM from 1981 to 2015 and GIS data of Gandhinagar town as well as field data was used.

\subsection{Remote Sensing (RS) Satellite Data}

Multi-temporal Satellite data of Landsat TM of different years from 1981 to 2015 for the month of January were downloaded from website:

https://earthexplorer.usgs.gov/ and used for mapping and monitoring urban sprawl of Gandhinagar town during last 35 years (Table 1). The Multi-temporal Landsat TM and MSS data covering Gandhinagar Town used in this study is given in Figure 3.

\subsection{Geographic Information System (GIS) Data}

The GIS data available with BISAG like: a) Gandhinagar Urban Development Area (GUDA) and Gandhinagar Municipal Corporation (GMC) Boundaries, b) Transport Network, etc. was used for preparation base maps of the study area. The base map of Gandhinagar Municipal Corporation showing lay-out of different sectors and transport network is given in Figure 4. 


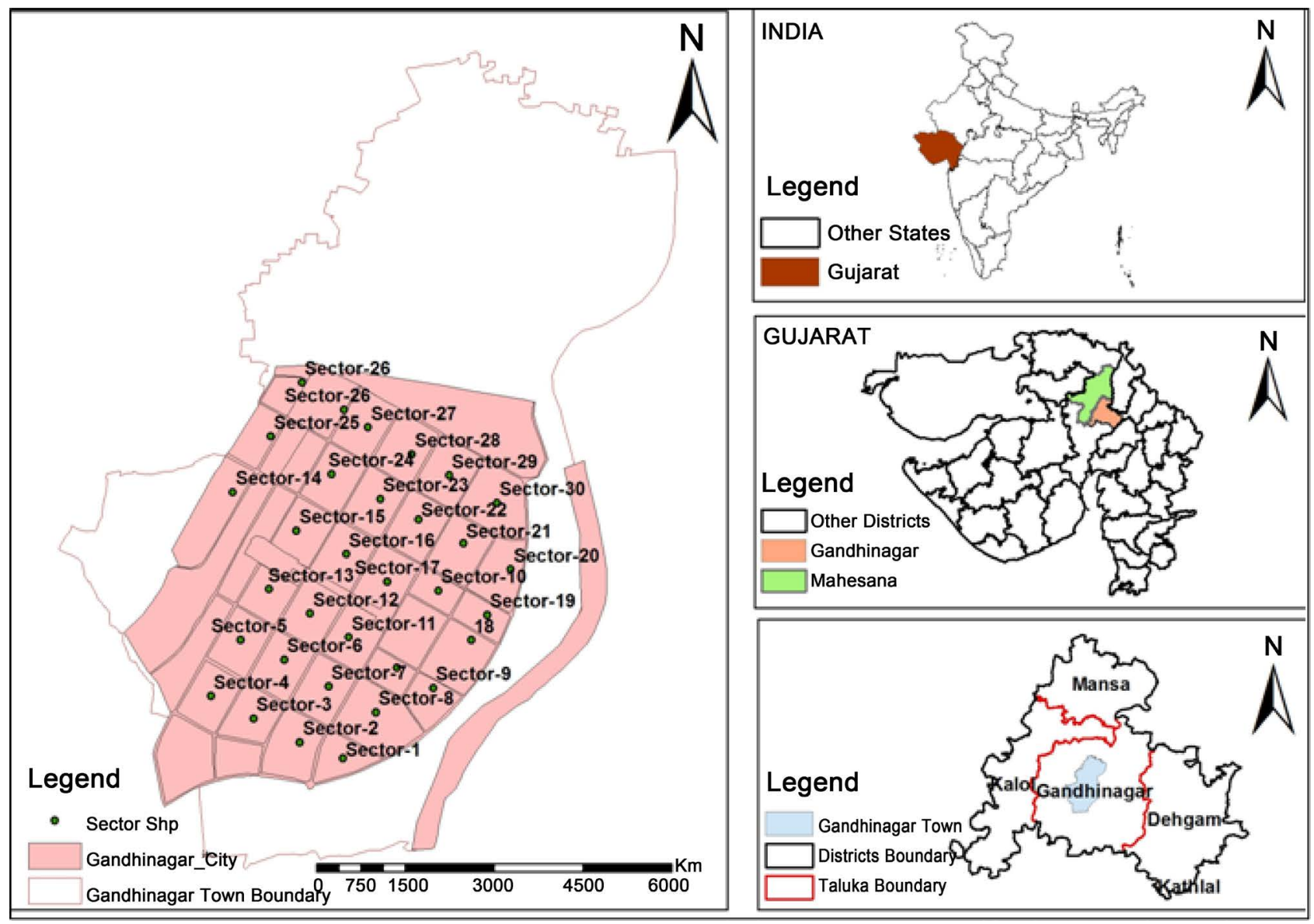

Figure 1. Location of the study area in Gujarat state.

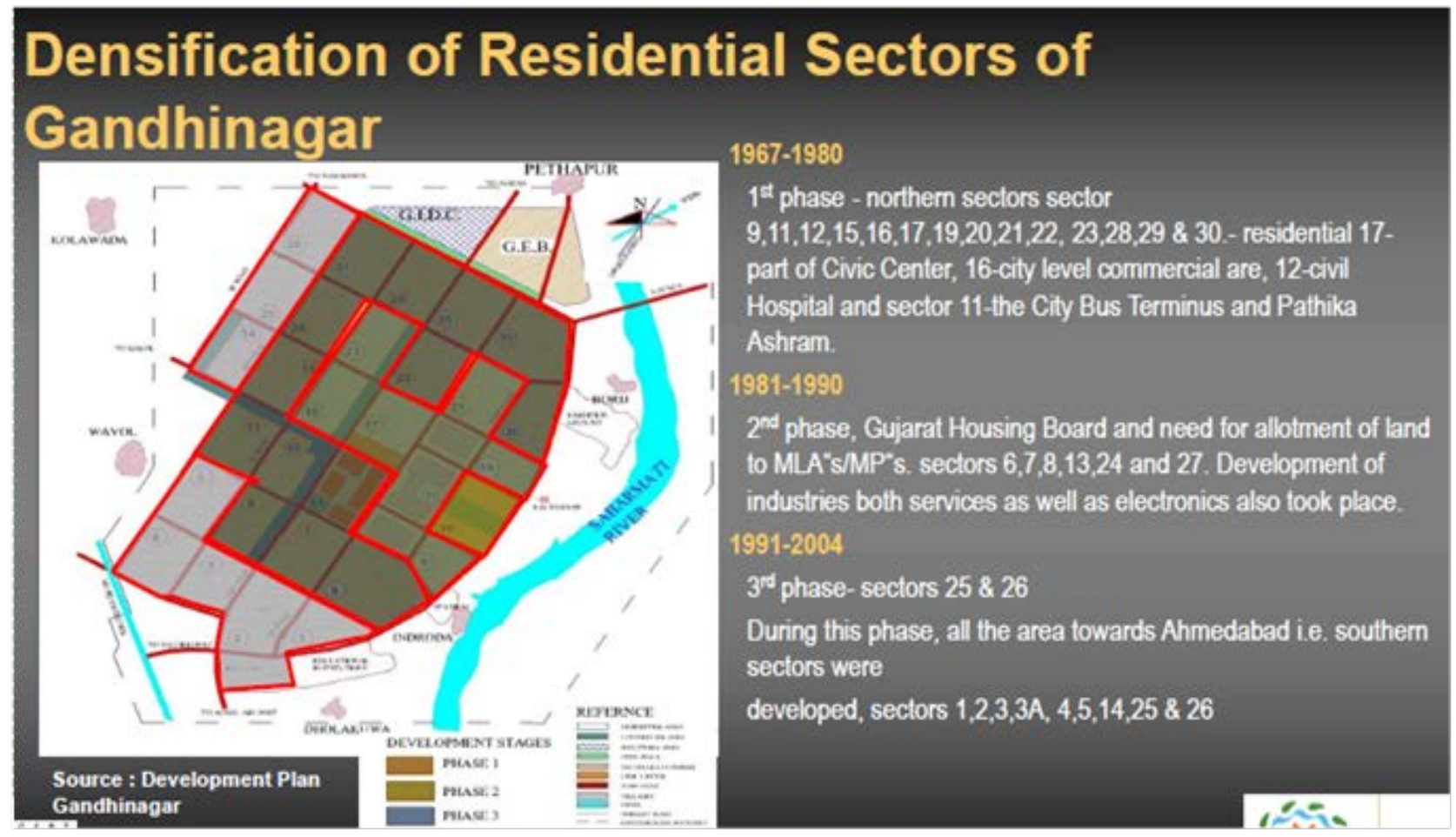

Figure 2. Development Plan of Gandhinagar indicating development during three phases. 
Table 1. Details of remote sensing satellite data used.

\begin{tabular}{cccccc}
\hline Sr. No. & Satellite & Sensor & Path/Row & Resolution & Date of Pass \\
\hline 1. & Landsat-4 & MSS & $148 / 045$ & $60 \mathrm{~m}$ & Jan-1981 \\
2. & Landsat-5 & TM & $148 / 045$ & $30 \mathrm{~m}$ & Jan-1989 \\
3. & Landsat-5 & TM & $148 / 045$ & $30 \mathrm{~m}$ & Jan-1995 \\
4. & Landsat-7 & TM & $148 / 045$ & $30 \mathrm{~m}$ & Jan-2000 \\
5. & Landsat-5 & TM & $148 / 045$ & $30 \mathrm{~m}$ & Jan-2011 \\
6. & Landsat-8 & TM & $148 / 045$ & $30 \mathrm{~m}$ & Jan-2015 \\
\hline
\end{tabular}
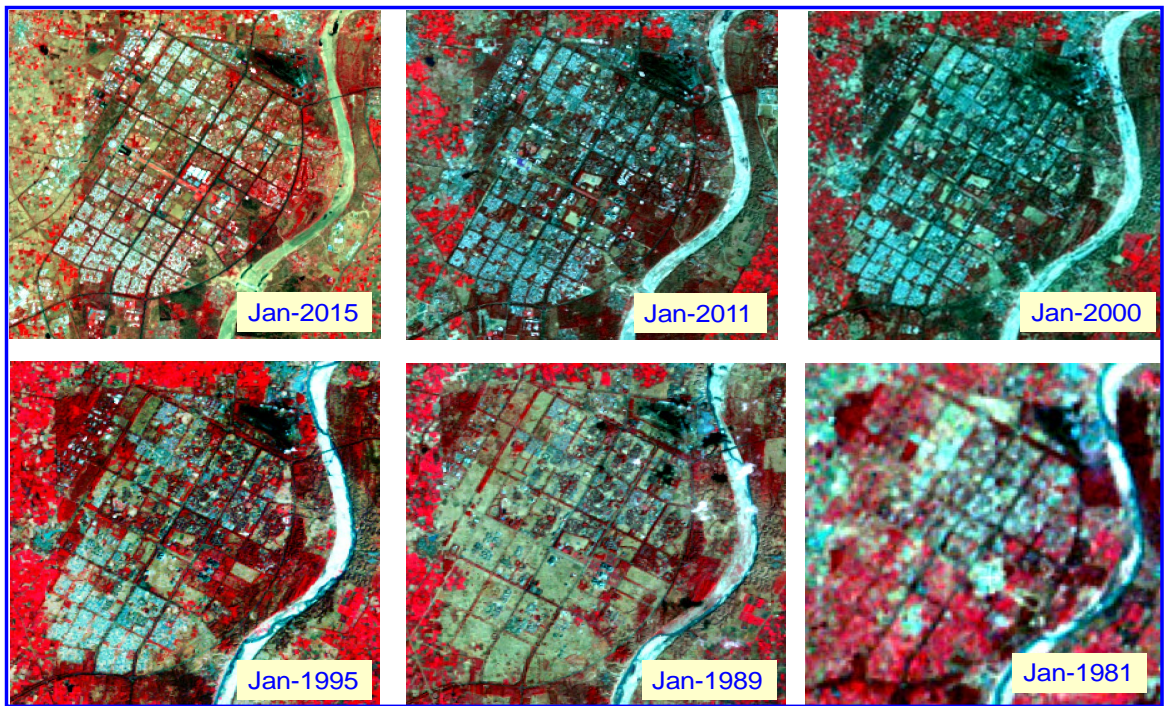

Figure 3. Multi-temporal Landsat TM data covering Gandhinagar Town.

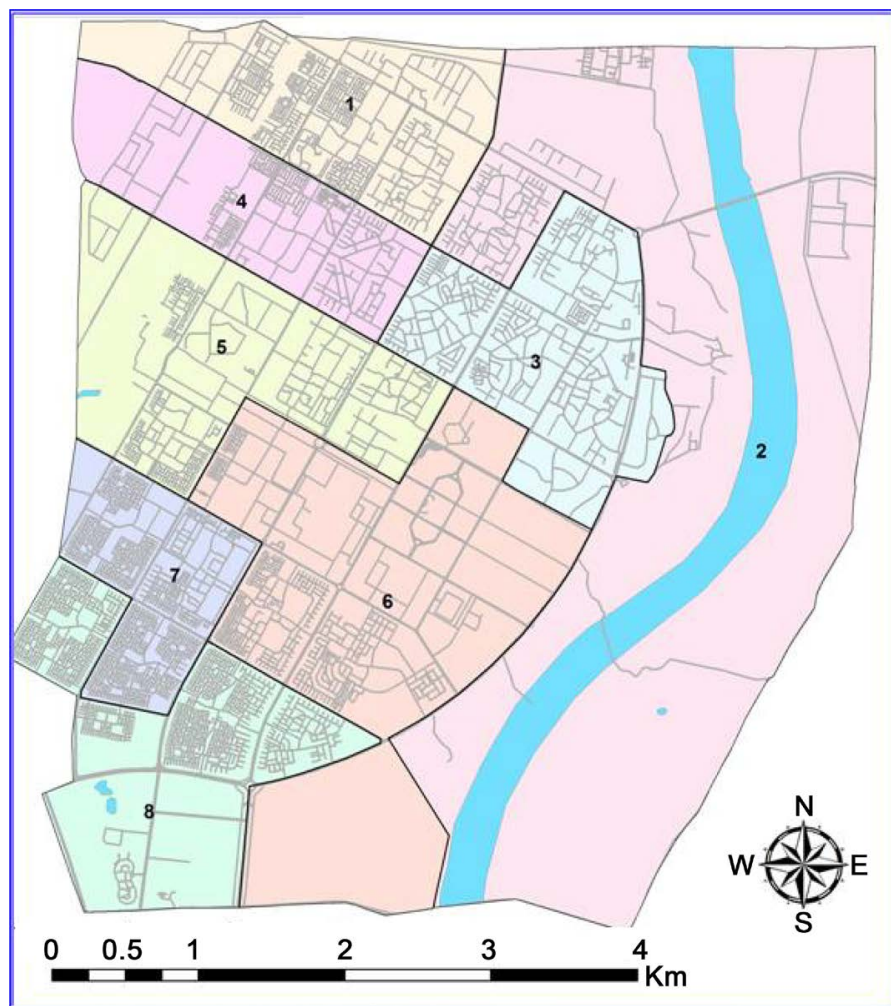

Figure 4. Lay out Plan of Gandhinagar indicating different sectors and transport network. 


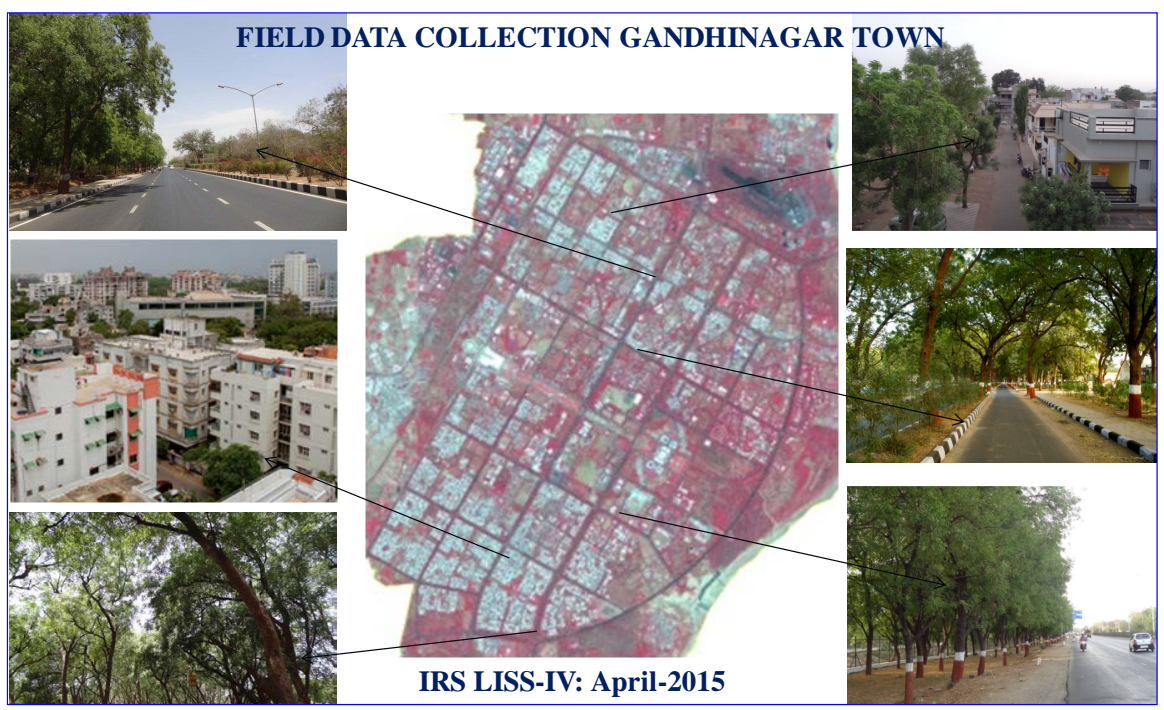

Figure 5. Field data collection on Tree cover and urban density in Gandhinagar Town.

\subsection{Field Data Collection}

Field data on tree cover and urban density in different parts of Gandhinagar town was collected and their Geographic coordinates of the visited fields were also recorded using GPS. These photographs were transferred on the satellite image for accurate area identification. Field photographs of tree cover and urban density in different areas of Gandhinagar town were geo-tagged for actual visualization of the field details and areas on the satellite data. The locations of field observations and geo-tagged photographs superimposed on the Satellite data covering Gandhinagar town are given in Figure 5.

\section{Data Analysis}

\subsection{Remote Sensing Satellite Data Analysis}

The multi-date Landsat images from 1981 to 2015 were downloaded and geometrically corrected using the Ground Control Points (GCPs) identified on image and Global Positioning System (GPS) measurements. Using these GCPs and GPS measurements, second order polynomials with nearest neighbour (NN) resampling procedure, the geo-referenced images were generated in Universal Transverse Mercator (UTM) projection with WGS 84 datum at $30 \times 30 \mathrm{~m}$ resolution. Root Mean Square (RMS) errors were within +0.5 to 0.75 pixels. The study area covering the Gandhinagar town was extracted from all different date images.

\subsection{Generation of Indices}

The traditional approaches of classification to extract built up areas remains laborious and has a high probability of misclassification between bare soil and constructed surfaces; this is due generally to the urban complexity, where spectral reflectance can represent a combination of several land cover called mixed pixels $(\mathrm{Wu}, 2004)$. However, the development of spectral indices helps in the 
correct interpretation of spatial remote sensing images in various domains, including urban planning, which the success of these indices is due generally to the combination of two or more land surface reflectance with different wavelengths.

Based on the analysis of the unique spectral responses of built-up areas and other land covers in seven Landsat TM bands, the original NDBI approach developed by Zha et al. (2003) was implemented and three indices based on Landsat TM bands covering visible Red (R), Near Infrared (NIR) and Short Wave Infrared (SWIR) wavelength regions were generated using following equations:

a) Normalized Difference Vegetation Index (NDVI):

$$
\text { NDVI }=\text { NIR }- \text { Red } / \text { NIR }+ \text { Red }
$$

b) Normalized Difference Built-up Index (NDBI):

$$
\text { NDBI }=\text { SWIR }- \text { NIR/SWIR + NIR }
$$

c) Built Up Index (BUI):

$$
\mathrm{BUI}=\mathrm{NDBI}-\mathrm{NDVI}
$$

In this study, the non-urban and urban built-up areas are distinguished based on a BUI and NBI. The Non-urban areas include urban vegetation including parks and gardens, open spaces, water and Agricultural vegetation. The urban areas were also identified into dense urban and sparse urban areas. Using these equations the images of NDVI, NDBI and BUI were generated and a colour composite image of NDVI and BUI was also generated. These images generated using 16-Jan-2015 Landsat TM data are given in Figure 6.

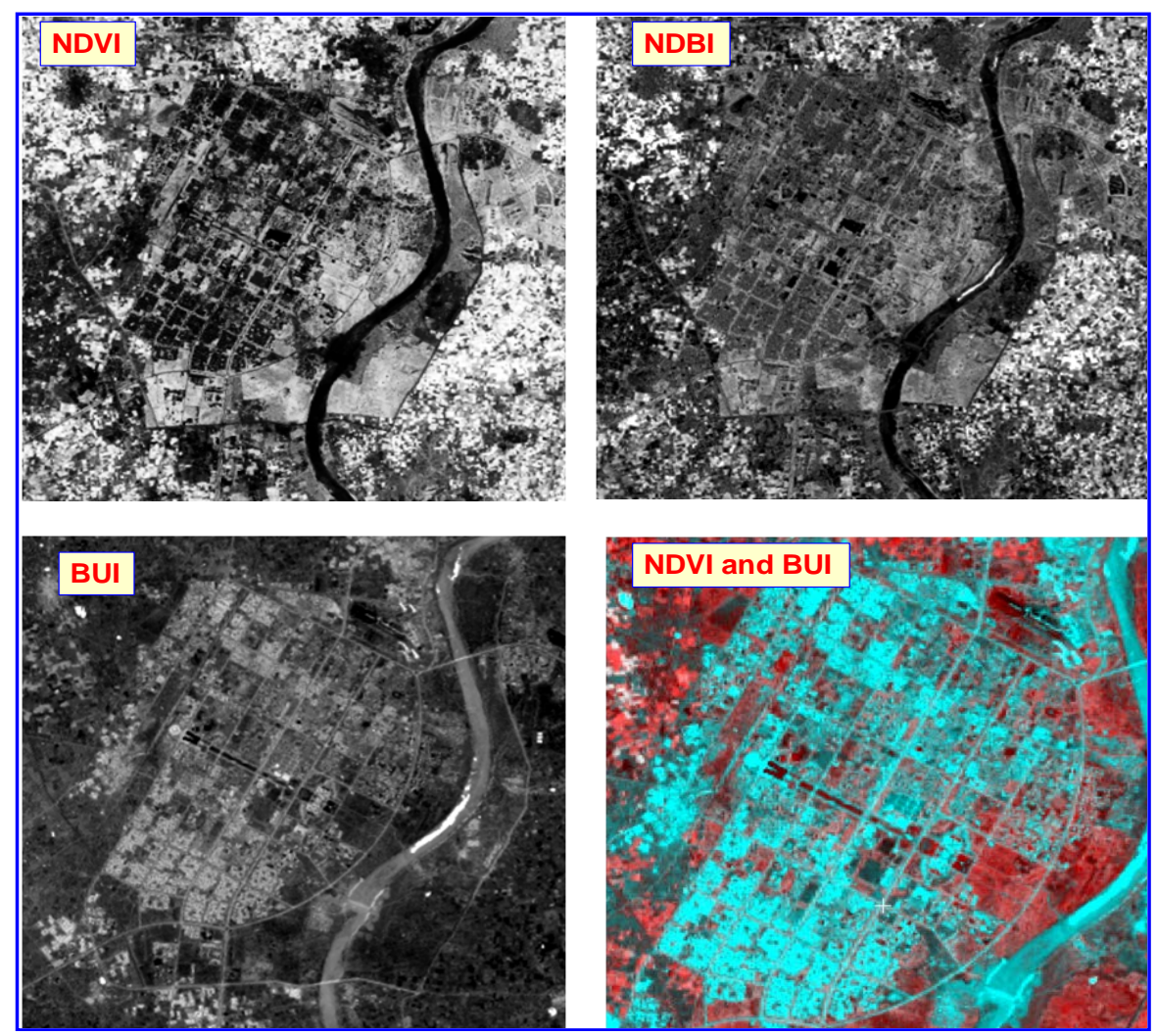

Figure 6. Images of three indices and composite of NDVI and BUI covering Gandhinagar. 


\section{Results and Discussion}

\subsection{Spectral Response of Urban Land Cover classes}

Spectral variations in built-up, open spaces, urban vegetation and water areas were studied, using sample areas of urban land cover types and DN values these classes were averaged to plot the graphs given in Figure 7. The DN values in four Landsat-8 TM bands namely Band3-Green (0.53 - $0.59 \mathrm{~nm}$ ), Band4-Red (0.64 - $0.67 \mathrm{~nm})$, Band5-NIR (0.85 - $0.88 \mathrm{~nm})$ and Band6-SWIR1 (1.57 - 1.65 $\mathrm{nm}$ ) of sample areas having more than 190 pixels were generated and average DN values for each cover type were generated. The spectral response of built up areas like Urban-dense and urban-sparse classes are quite distinct from other cover types like open spaces, urban vegetation and water.

\subsection{Relationships among NDBI, NDVI and BUI}

Zha, Gao and Ni (2003) developed the NDBI on the footprints of the NDVI that used Landsat Thematic Mapper (TM) near-infrared (NIR) band 4 (low reflectance in built-up area) and mid-infrared (MIR) band 5 (high reflectance in built-up area). The output NDBI was further refined by removing vegetation noise using NDVI. He et al. (2010) found in their studies that NDBI generated using TM band $4(0.76-0.90 \mu \mathrm{m})$ and TM band $5(1.55-1.75 \mu \mathrm{m})$ were most suitable for discriminating built-up areas from other land cover types.

In this study three indices namely, NDVI, NDBI and BUI were generated using the Equations (1)-(3) given above and given in Figure 6. The built-up areas are seen as white and bright grey tones on the BUI image, where as the other

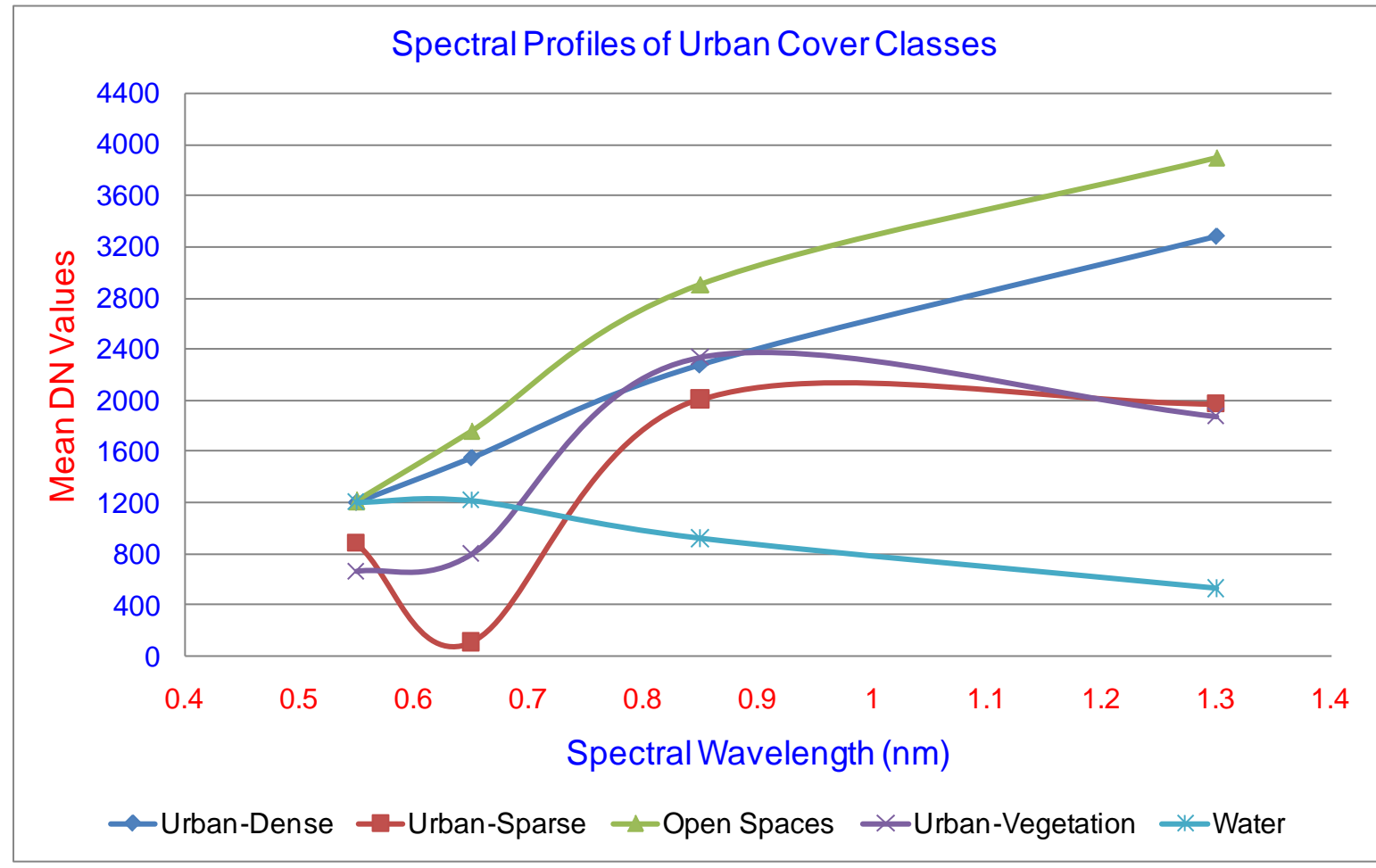

Figure 7. Spectral Profiles of Urban land cover types using Landsat-TM data. 
Table 2. Mean and Standard Deviations of various urban land use classes in NDVI, NDBI and BUI images.

\begin{tabular}{cccccccc}
\hline Class & \multirow{2}{*}{ Npix } & \multicolumn{2}{c}{ NDVI } & \multicolumn{2}{c}{ NDBI } & \multicolumn{2}{c}{ BUI } \\
\hline & & Mean & Std Devi & Mean & Std Devi & Mean & Std Devi \\
\hline Urban-Dense & 251 & 0.189 & 0.033 & $-9.87 \mathrm{E}-03$ & 0.025 & $-3.77 \mathrm{E}-01$ & 0.035 \\
Urban-Sparse & 294 & 0.295 & 0.073 & $2.63 \mathrm{E}-02$ & 0.046 & $-2.67 \mathrm{E}-01$ & 0.052 \\
Open Spaces & 167 & 0.247 & 0.028 & $-1.33 \mathrm{E}-01$ & 0.032 & $-3.77 \mathrm{E}-01$ & 0.024 \\
Urban-Veg. & 346 & 0.575 & 0.046 & $1.68 \mathrm{E}-01$ & 0.049 & $-4.04 \mathrm{E}-01$ & 0.025 \\
Agri.-Veg. & 156 & 0.688 & 0.095 & $2.77 \mathrm{E}-01$ & 0.118 & $-4.11 \mathrm{E}-01$ & 0.039 \\
Water & 54 & -0.176 & 0.068 & $4.00 \mathrm{E}-01$ & 0.057 & $5.98 \mathrm{E}-01$ & 0.107 \\
\hline
\end{tabular}

land cover types are seen as light grey, dark grey and black tones. Also Densely vegetated areas appear dark black tones. The water in the river and other places in the town are seen as very bright white in colour. The urban vegetation as well agricultural crops are seen as bright pink and red tones in the composite image of NDVI \& BUI. The spectral responses of built-up, vegetation and water areas in the NDVI, NDBI and BUI images were generated using the sample areas of various classes on these images. The number of pixels used to generate the statistics along with mean values and Standard Deviations of each class are given in Table 2.

The urban land cover types have quite distinct signature in all the three spectral indices which indicates that these land cover types can be segregated from each other using these indices. The scatter plots of various urban land cover types in two-dimensional spectral space of NDBI and BUI were also generated to monitor their spectral separability (Figure 8). The scatter plots given in Figure 7 indicate very distinct separation in spectral responses of built-up, urban vegetation and water classes in NDBI and BUI images. The clusters of open spaces, urban vegetation and water are quite distinct and well separated from built-up areas indicating that urban built-up areas are clearly separable using the NDBI and BUI. However, there is some overlap among the urban-dense and urbansparse built-up categories but nevertheless these two urban classes are quite distinct from open spaces and urban vegetation.

\subsection{Built-up area Extraction using NDBI in Gandhinagar}

The area under urban land use classes like built-up area, open spaces and urban vegetation classes were estimated using the false colour composite images generated using NDVI and BUI images of different years. The estimated area under built-up, open spaces and urban vegetation in Gandhinagar town during 1989 to 2015 is given in Table 3. The changes in Urban Land cover types in Gandhinagr during 1989 to 2015 are also plotted in Figure 9.

The built-up area in Gandhinagar increased from 1100.1 ha during Jan 1989 to 1907.3 ha during Jan 2015 which indicates about 73 per cent increase in the built-up area during the period of 26 years. The urban vegetation which includes 
parks and gardens in the city has also shown increasing trend during the period of 1989 to 2015. However, the area under open spaces has decreased as the development of built-up area has increased as per development plan of the Gandhinagar town. The development of Gandhinagar has been carried out in three

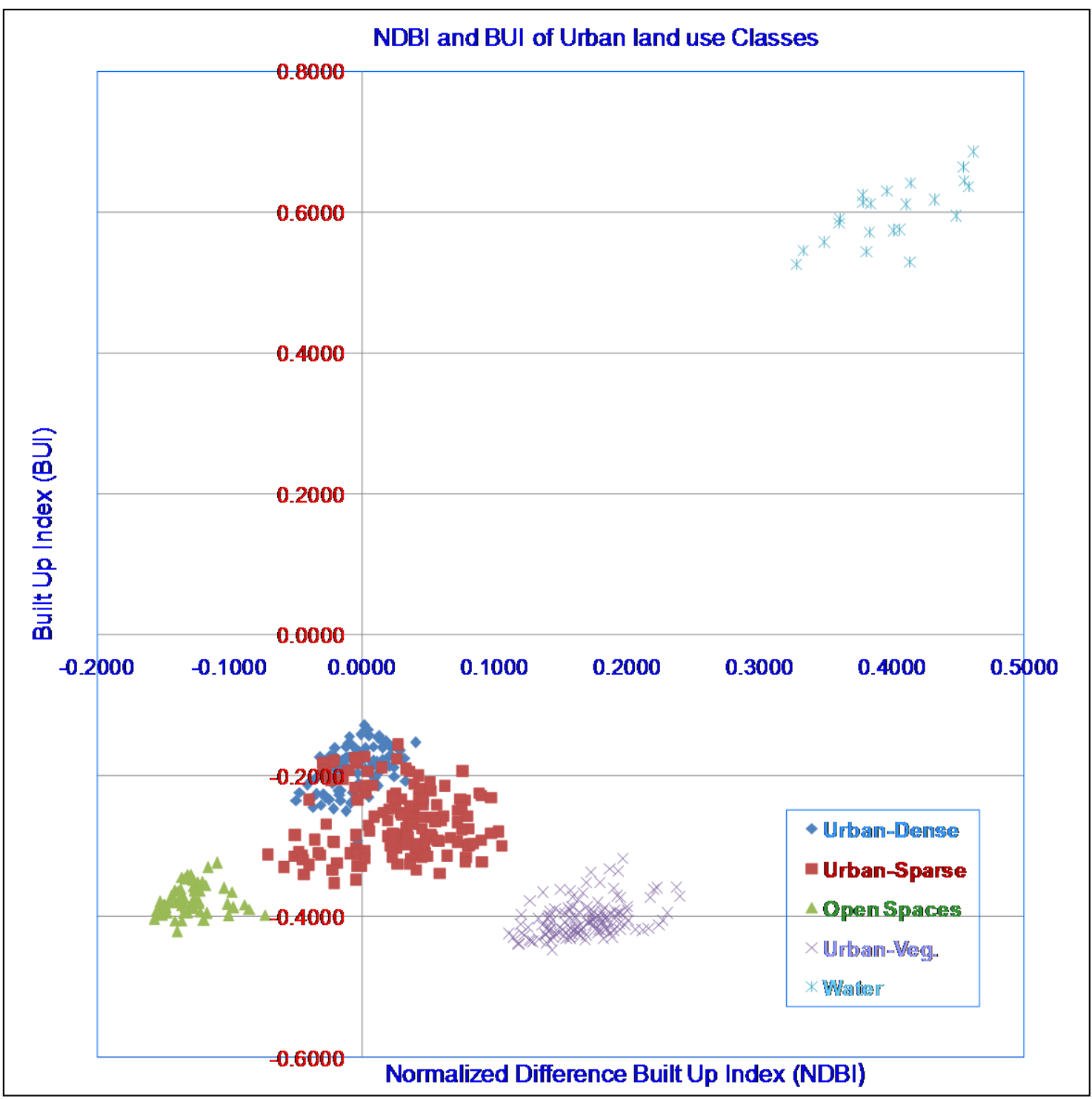

Figure 8. Scatter plots of urban land cover types in NDBI and BUI spectral space.

Table 3. Area under Urban land cover in Gandhinagar during 1989 to 2015.

\begin{tabular}{lllll}
\hline Sr. No. & Month-Year & Area (ha) under Urban Land Cover Type & \\
1. & Built-Up & Open Spaces & Urban Vegetation \\
2. & January 1989 & 1100.7 & 1147.0 & 598.5 \\
3. & January 1995 & 1599.1 & 566.5 & 680.6 \\
4. & January 2000 & 1706.6 & 304.1 & 835.5 \\
5. & January 2011 & 1824.1 & 151.1 & 871.0 \\
\hline
\end{tabular}




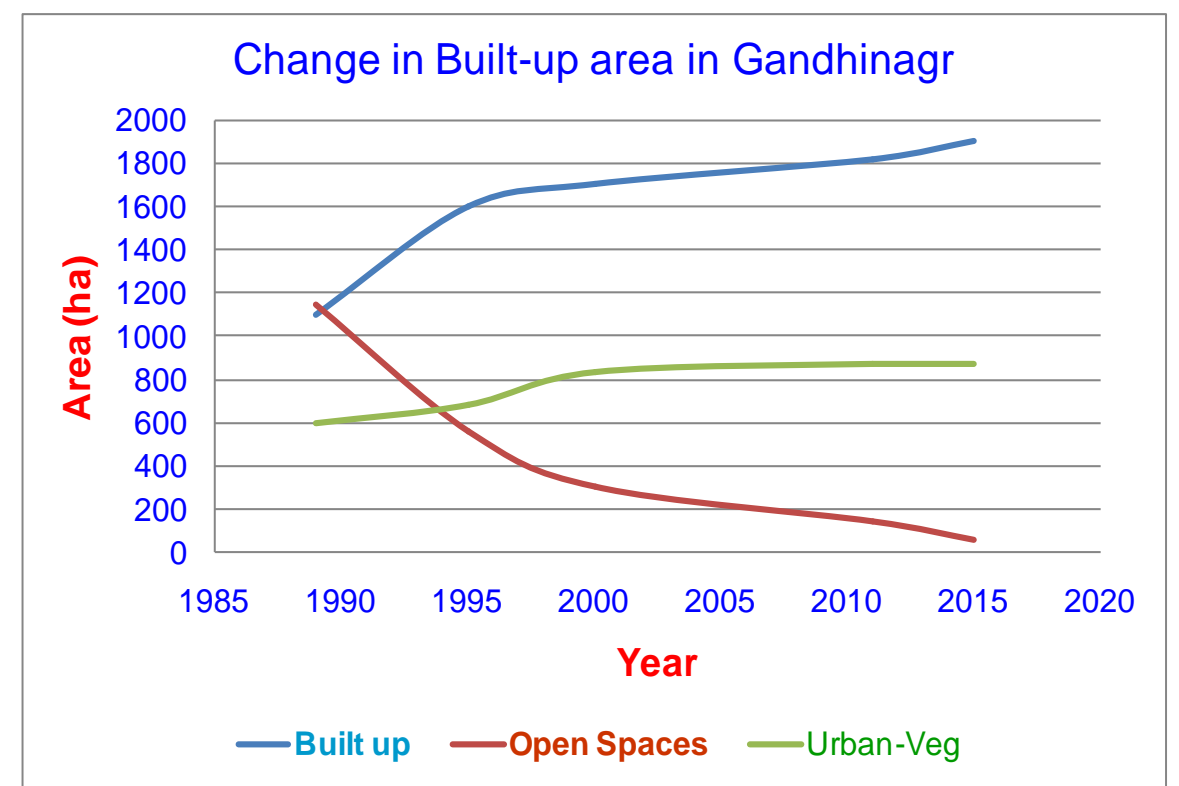

Figure 9. Changes in Urban Land cover types in Gandhinagr during 1989 to 2015.

phases as given in Figure 2. During Phase-I (1967 -1980) only northern part was under development. During Phase-II (1981-1990) and Phase-III (1991-2004) most of the sectors in the town were under development and after 2005 to 2015 all the sectors were fully developed with increasing built-up area. This activity of increase in built-up area in different sectors can be clearly seen in Landsat images from 1989 to 2015 given in Figure 3.

\section{Conclusions}

The present study urban growth in Gandhinagar town was monitored using Geospatial technology and multi-temporal Remote Sensing Satellite data of last 35-years. Landsat MSS and TM data from 1981 to 2015 was analysed for urban sprawl mapping. The field data on built-up areas, open spaces, urban vegetation including parks, gardens and tree clusters etc. was also collected in different sectors of Gandhinagar town. To identify and delineate urban built areas and other urban cover types, various indices like of Normalized Difference Vegetation Index (NDVI), Normalized Difference Built-up Index (NDBI) and Built-Up Index (BUI) were generated using Landsat TM data covering Gandhinagar town.

The major conclusions of this study are as follows:

- Spectral variations in built-up, open spaces, urban vegetation and water areas were studied by generating two-dimensional spectral plots of NDBI and BUI. The spectral response of built up areas like Urban-dense and urban-sparse classes are quite distinct from other cover types like open spaces, urban vegetation and water.

- The results indicate that the normalized difference built-up index (NDBI) and Built-up Index (BUI) were very useful for mapping urban built-up areas in Gandhinagar town using Landsat Thematic Mapper (TM) data.

- The area under urban land use classes like built-up area, open spaces and ur- 
ban vegetation classes were estimated using the false colour composite images generated using NDVI and BUI images of different years.

- The built-up area in Gandhinagar increased from 1100.1 ha during Jan 1989 to 1907.3 ha during Jan 2015 which indicates about 73 per cent increase in the built-up area during the period of 26 years.

\section{Acknowledgements}

The authors express their sincere thanks to Shri T. P. Singh, Director, Bhaskarcharya Institute for Space Applications and Geo-informatics (BISAG), Department of Science \& Technology, Government of Gujarat, Gandhinagar for his encouragement and guidance to conduct this study.

\section{References}

[1] Theobald, D.M. (2001) Quantifying Urban and Rural Sprawl Using the Sprawl Index. Proceedings of the Association of American Geographers, New York, 2 March 2001, 544-564.

[2] Bugliarello, G. (2003) Large Urban Concentrations: A New Phenomenon. In: Reader, A., Heiken, G., Fakundiny, R. and Sutter, J., Eds., Earth Science in the City, American Geophysical Union, New York, 7-19. https://doi.org/10.1029/sp056p0007

[3] Torrens, P.M. and Alberti, M. (2000) Measuring Sprawl. Working Paper No. 27, Centre for Advanced Spatial Analysis, University College, London.

[4] Barnes, K.B., Morgan III, J.M., Roberge, M.C. and Lowe, S. (2001) Sprawl Development: Its Patterns, Consequences, and Measurement. Towson University, Towson.

[5] Bhatta, B., Saraswati, S. and Bandopadhyay, D. (2010) Urban Sprawl Measurement from Remote Sensing Data. Applied Geography, 30, 731-740.

[6] Xian, G. and Crane, M. (2006) An Analysis of Urban Thermal Characteristics and Associated Land Cover in Tampa Bay and Las Vegas Using Satellite Data. Remote Sensing of Environment, 104, 147-156.

[7] Kaufmann, R.K., Seto, C.K., Schneider, A., Liu, Z., Zhou, L. and Wang, W. (2007) Climate Response to Rapid Urban Growth: Evidence of a Human-Induced Precipitation Deficit. Journal of Climate, 20, 2299-2306.

https://doi.org/10.1175/JCLI4109.1

[8] Xu, H. (2008) A New Index for Delineating Built-Up Land Features in Satellite Imagery. International Journal of Remote Sensing, 29, 4269-4276. https://doi.org/10.1080/01431160802039957

[9] Melesse, A.M., Weng, Q., Thenkabail, P.S. and Senay, G.B. (2007) Remote Sensing Sensors and Applications in Environmental Resources Mapping and Modelling. Sensors, 7, 3209-3241. https://doi.org/10.3390/s7123209

[10] Weng, Q. (2008) Remote Sensing of Impervious Surfaces: An Overview. In: Weng, Q., Ed., Remote Sensing of Impervious Surfaces, CRC Press, Taylor \& Francis Group, Boca Raton.

[11] Boori, M.S., Netzband, M., Choudhary, K. and Vozenilek, V. (2015) Monitoring and Modeling of Urban Sprawl through Remote Sensing and GIS in Kuala Lumpur, Malaysia. Ecological Processes, 4, 15.

[12] Griffiths, P., Hostert, P., Gruebner, O. and Van Der Linden, S. (2010) Mapping Megacity Growth with Multi-Sensor Data. Remote Sensing of Environment, 114, 426-439. 
[13] Tewolde, M.G. and Cabral, P. (2011) Urban Sprawl Analysis and Modeling in Asmara, Eritrea. Remote Sensing, 3, 2148-2165.

[14] Jat, M.K., Garg, PK. and Khare, D. (2008) Monitoring and Modelling Urban Sprawl Using Remote Sensing and GIS Techniques. International Journal of Applied Earth Observation, 10, 26-43.

[15] Wei, J., Jia, M., Twibell, R.W. and Underhill, K. (2006) Characterizing Urban Sprawl Using Multistage Remote Sensing Images and Landscape Metrics. Computers Environment and Urban Systems, 30, 861-879.

[16] Rahman, A., Agarwal, S.P., Netzband, M. and Fazal, S. (2010) Monitoring Urban Sprawl Using Remote Sensing and GIS Techniques of a Fast Growing Urban Centre, India. Applied Earth Observations and Remote Sensing, 4, 56-64.

[17] Silambarasan, K., Vinaya, M.S. and Sureshbabu, S. (2014) Urban Sprawl Mapping and Landuse Change Detection in and around Udupi Town: A Remote Sensing Based Approach. International Journal of Scientific Research Engineering and Technology, 2, 815-820.

[18] Firoz, A. and Laxmi, G. (2016) Analysis of Urban Sprawl Dynamics Using Geospatial Technology in Ranchi City, Jharkhand, India. Journal of Environmental Geography, 9, 7-13.

[19] Guindon, B., Zhang, Y. and Dillabaugh, C. (2004) Landsat Urban Mapping Based on a Combined Spectral-Spatial Methodology. Remote Sensing of Environment, 92, 218-232.

[20] Zha, Y., Gao, J. and Ni, S. (2003) Use of Normalized Difference Built-Up Index in Automatically Mapping Urban Areas from TM Imagery. International Journal of Remote Sensing, 24, 583-594. https://doi.org/10.1080/01431160304987

[21] He, C., Shi, P., Xie, D. and Zhao, Y. (2010) Improving the Normalized Difference Built-Up Index to Map Urban Built-Up Areas Using a Semiautomatic Segmentation Approach. Remote Sensing Letters, 1, 213-221. https://doi.org/10.1080/01431161.2010.481681

[22] Kaimaris, D. and Patias, P. (2016) Identification and Area Measurement of the Built-Up Area with the Built-Up Index (BUI). International Journal of Advanced Remote Sensing and GIS, 5, 1844-1858. https://doi.org/10.23953/cloud.ijarsg.64

\section{Scientific Research Publishing}

Submit or recommend next manuscript to SCIRP and we will provide best service for you:

Accepting pre-submission inquiries through Email, Facebook, LinkedIn, Twitter, etc. A wide selection of journals (inclusive of 9 subjects, more than 200 journals)

Providing 24-hour high-quality service

User-friendly online submission system

Fair and swift peer-review system

Efficient typesetting and proofreading procedure

Display of the result of downloads and visits, as well as the number of cited articles

Maximum dissemination of your research work

Submit your manuscript at: http://papersubmission.scirp.org/

Or contact ijg@scirp.org 